\title{
CARDIOPROTECTIVE ACTIVITY OF CHITOSAN-Pinus merkusii EXTRACT NANOPARTICLES AGAINST LEAD ACETATE INDUCED CARDIAC CELL DAMAGE IN RAT
}

\author{
S. A. Sudjarwo ${ }^{1, *}$, C. Anwar ${ }^{2}$, K. Eraiko ${ }^{3}$, G. Wardani ${ }^{4}$ and Koerniasari ${ }^{5}$ \\ ${ }^{1}$ Department of Pharmacology, Faculty of Veterinary Medicine, \\ Airlangga University, Surabaya 60115, Indonesia \\ ${ }^{2}$ Department of Histology, Faculty of Veterinary Medicine, \\ Airlangga University, Surabaya 60115, Indonesia \\ ${ }^{3}$ Department of Conservative Dentistry, Faculty of Dentistry, \\ Airlangga University, Surabaya 60115 Indonesia, \\ ${ }^{4}$ Department of Pharmacy-Biology, Faculty of Pharmacy, \\ Hang Tuah University, Surabaya 60115 Indonesia, \\ ${ }^{5}$ Department of Microbiology, Study Program of Environmental Health, \\ Polytechnic of Health, Surabaya 60115 Indonesia \\ *E-mail: ags158@yahoo.com.
}

\begin{abstract}
This study, we investigated the role of Chitosan-Pinus merkusii extracts nanoparticle in against lead acetate-induced cardiac cell damage in rat. Chitosan-Pinus merkusii extract nanoparticle was characterized by Scanning Electron Microscope (SEM) and Dynamic Light Scattering (DLS). The fifty rats were divided into: control group (rats were given with distilled water); lead acetate group (rats were injected with lead acetate $15 \mathrm{mg} / \mathrm{kg}$ body weight i.p.), and the treatment group (rats were given the chitosan-Pinus merkusii nanoparticle $100 \mathrm{mg} ; 200 \mathrm{mg} ; 400 \mathrm{mg} / \mathrm{kg}$ body weight orally and were injected with lead acetate $15 \mathrm{mg} / \mathrm{kg} \mathrm{BW}$ ). The blood was taken to be measured lactate dehydrogenase (LDH) and Creatinine Kinase-MB (CK-MB) level. Also the cardiac tissues were collected to evaluate the malondialdehyde (MDA), superoxide dismutase (SOD), glutathione peroxidase (GPx), and histological evaluations of heart damage. The size of Chitosan-Pinus merkusii extract nanoparticle in the DLS was $201.8 \pm 14.6$ $\mathrm{nm}$, while in the SEM showed an irregular shape and rough surface. The lead acetate significant increased LDH, CKMB,MDA, and decreased SOD, GPx. Histological analysis, lead acetate also induced necrosis in the cardiac cell. However, treatment with the Chitosan-Pinus merkusii extract nanoparticle, only dose $400 \mathrm{mg} / \mathrm{kg} \mathrm{BW}$ significantly decreased LDH, CK-MB, MDA, and increased SOD, GPx levels. The Chitosan-Pinus merkusii extract nanoparticle $400 \mathrm{mg} / \mathrm{kg} \mathrm{BW}$ also demonstrated significantly improved cardiac cell damage. From the results, it is concluded that the Chitosan-Pinus merkusii nanoparticle is a potent antioxidant in against lead acetate-induced cardiotoxicity in rats. Keywords: Chitosan-Pinus merkusii extract nanoparticle, Lead acetate, Cardiac cells, LDH, CK-MB, MDA, Antioxidant
\end{abstract}

@ ( RASĀYAN. All rights reserved

\section{INTRODUCTION}

Environmental pollution and exposure to heavy metals is a serious growing problem throughout the world the last decades. Lead acetate is one of a non-essential toxic heavy metal which can cause extensive environmental pollution and problems in almost all the body tissues (bones, lung, kidneys, liver, reproductive organs, immune system, and heart) of human and animal. ${ }^{1}$ It has been reported that lead acetate causing neurotoxicity, hepatotoxicity, nephrotoxicity, gastrotoxicity, reproductive systems toxicity, and cardiotoxicity. ${ }^{2,3,4}$ Previous studies also have reported that toxicity of lead $(\mathrm{Pb})$ has been

Rasayan J. Chem., 12(1), 184-191(2019)

http://dx.doi.org/10.31788/RJC.2019.1215049 
associated with cardiovascular disease. There is an association between heart disease and lead acetate toxicity. ${ }^{5}$

The mechanism of lead-induced cardiotoxicity is the oxidative stress, through the increased production of reactive oxygen species (ROS) or free radicals such as hydroxyl radical $\left(\mathrm{OH}^{-}\right)$, nitric oxide (NO) and superoxide ion $\left(\mathrm{O}_{2}^{-}\right)$, and the decreasing antioxidants such as glutathione peroxidase (GPx), superoxide dismutase (SOD) and Catalase (CAT) in the heart. ${ }^{6,7,8} \mathrm{In}$ addition, ROS are the major contributing factors to stress injuries on membrane lipids, protein, and DNA, and to cause rapid cellular damage. It was also reported that Malondialdehyde (MDA) is secondary products of lipid peroxidation, may be utilized as a marker of cardiac cell damage. The increasing concentration of MDA is evidence of heart tissue damage of lead toxicity processes caused by increased free radicals. ${ }^{2,4}$

Recent studies have shown that several antioxidants of the natural product have protective effects against lead-induced oxidative damage and free radical generated formation in the body. Natural products are easily found as sources of antioxidants which contain a mixture of different chemical compounds to improve health and to treat diseases. ${ }^{9}$ Antioxidant activity or inhibition of generation of free radicals plays important role in prevention against such cardiotoxicity. So, it has been claimed that protective agents such as antioxidants, may be used to preventive on heavy metal toxicity in the heart. ${ }^{10}$ The advantage of using natural products or herbal medicine for the treatment of various diseases was low cost and little side effects compared with a conventional drug. ${ }^{11}$ Many authors tried herbal medicine like Nigella sativa ${ }^{7}$, Murraya koenigii ${ }^{6}$, Curcuma longa ${ }^{12}$ against lead-induced cardiac cell damage.

This study has been focused on the protective effect of natural products or herbal medicine having antioxidant properties of Chitosan-Pinus merkusii for protective in reducing free radical-induced cardiac cell damage. It has been demonstrated that Pinus plant was due to the phytochemicals possessed, including alkaloids, polyphenols, flavonoids, lignans, triterpenes, sterols, glycosides, triterpenoids, and saponins ${ }^{14,15}$. Recent research activities have shown that Pinus plant is an important source of pycnogenol that contains proanthocyanidins (procyanidins). ${ }^{16-18}$ Proanthocyanidins are potent, free radical scavengers, antibacterial agents, exhibit vasodilatory, anti-allergic, anti-inflammatory, cardioprotective, immune-stimulating, antiviral, and estrogenic activities. ${ }^{18-20}$

In recent years, the synthesis of natural product nanoparticles is an interesting issue of the nanoscience and nanobiotechnology ${ }^{21}$. There is growing attention to biosynthesis the nanoparticles using a natural product, and they are suitable for large-scale biosynthesis of nanoparticles. In medicine, natural product nanoparticles are used as therapeutic agents to more efficient into the target site. Nanoparticle have advantages such as better bioavailability, solubility and efficacy. ${ }^{22}$

Chitosan is one of natural product reported is widely used in pharmaceutical and biomedical applications ${ }^{23,24}$ Chitosan nanoparticles have drawn the attention of researchers for their experiment and are used for both invitro and invivo applications. ${ }^{25,26}$ Its also non-toxic and are known to possess many biological activities such as antibacterial, antioxidant, anti hyperlipidemia, anti-diabetic, anti-HIV, antiinflammatory activities, drug delivery, and immune enhancing, make it an ideal delivery agent for applications in medicine. ${ }^{27-29}$ Chitosan-Pinus merkusii extract nanoparticle is more stable, and the rate of synthesis is faster than that in the case of other organisms. The aim of the present study was to investigate the cardioprotective activity of the Chitosan-Pinus merkusii extract nanoparticle on lead-induced cardiac cell damage in Wistar albino rats.

\section{Chemicals}

\section{EXPERIMENTAL}

Lead acetate was obtained from Sigma-Aldrich (Cat. No 6080-56-4), USA. The assay kit of MDA in tissues was purchased from NWLSS (Cat. No. NWK MDA01), USA. The measurement of tissue levels of SOD and GPx activities was performed using assay kits from Cayman Chemicals (Cat. No. 706002 and 703102, respectively), USA.

\section{Preparation of Chitosan-Pinus Merkusii Nanoparticles}

Chitosan-Pinus merkusii extract nanoparticle was prepared using ionotropic gelation method. ${ }^{15,30}$ The $0.2 \%(\mathrm{w} / \mathrm{v})$ solution of chitosan was made in $0.1 \%(\mathrm{v} / \mathrm{v})$ glacial acetic acid and then filtered. 
The $0.1 \%(\mathrm{w} / \mathrm{v})$ solution of tripolyphosphate (TPP) was made in deionized water. Under constant stirring, $0.4 \%(\mathrm{w} / \mathrm{v})$ extract of Pinus merkusii in $70 \%$ ethanol was added to $0.2 \%(\mathrm{w} / \mathrm{v})$ solution of chitosan, and then sonicated for $5 \mathrm{~min}$. Furthermore, under constant stirring, TPP solution was added dropwise. The ratio of chitosan : TPP solution was maintained at $2: 1$. The supernatant was centrifuged at $25000 \mathrm{rpm}$ for $20 \mathrm{~min}$, and then sediment of chitosan-Pinus merkusii was characterized.

\section{Characterization of Nanoparticles by Scanning Electron Microscopy and Dynamic Light Scattering} The surface morphological features such as particle size, shape and topography of the Chitosan-Pinus merkusii extract nanoparticle were observed using SEM.

Dynamic light scattering was done using Malvern Instruments version 2.2. The average particle size of the Chitosan-Pinus merkusii extract nanoparticle was determined.

\section{Experimental Animal}

The male Wistar rat was used in this research with weighing about 200-250 g (2.5-3 months) were purchased from Gadjah Mada University, Yogyakarta, Indonesia. The rats were housed in cages with a room temperature maintained at $26 \pm 2{ }^{\circ} \mathrm{C}$ and given feed and water drink ad libitum. This study was reviewed by the Ethical Clearance Committee for preclinical research, Institute of Tropical Disease, Airlangga University and obtained ethical clearance under No.179/ITD/1/2018. Date: May 10, 2018.

\section{Experimental Design}

The 50 male rats were divided into: control group (rats were given with distilled water); lead acetate group (rats were injected i.p. with lead acetate $15 \mathrm{mg} / \mathrm{kg}$ body weight), and the treatment group (rats were given orally the chitosan-Pinus merkusii nanoparticle $100 \mathrm{mg} / \mathrm{kg}, 200 \mathrm{mg} / \mathrm{kg}, 400 \mathrm{mg} / \mathrm{kg} \mathrm{BW}$ once a day for 11 days, and on 4th day rats were injected i.p. with lead acetate solution at a dose of $15 \mathrm{mg} / \mathrm{kg} \mathrm{BW}$ one hour after the chitosan-Pinus merkusii extract nanoparticle). On day 11, the rat's blood samples were taken by cardiac puncture to be measured LDH and CK-MB levels. Furthermore, rats were sacrificed, and cardiac tissues were homogenized with $50 \mathrm{mM}$ sodium phosphate buffer $(\mathrm{pH} 7.4)$ containing $0.1 \mathrm{mM}$ ethylene diamine tetra acetic acid. The supernatant was centrifuged at $1000 \mathrm{~g}$ for $20 \mathrm{~min}$ at $4{ }^{\circ} \mathrm{C}$. The supernatant was used for the analyzes of MDA and antioxidant enzymes (SOD and GPx). The heart was also fixed in a $10 \%$ neutral buffered formalin solution for histo pathological evaluation of the heart damage

\section{Measurement of Lactate Dehydrogenase and Creatine Kinase-MB Fraction}

The serum was analyzed for the presence of enzymes related to cardiac cells damage such as LDH and CK-MB ${ }^{8,10}$. All analysis was conducted with commercially assay kits according to the manufacturer's instructions

\section{Measurement of MDA}

The supernatant of homogenate heart tissue was measured to determine MDA level by the thiobarbituric acid method, on the absorbance at $532 \mathrm{~nm}$, which was expressed in nanomoles MDA/g tissue. ${ }^{2}$

\section{Measurement of Antioxidant Enzymes}

The SOD activity was measured with a kit of SOD detection according to the manufacturer's instructions. The level of SOD was measured at $505 \mathrm{~nm}$, which was expressed in U/mg protein. ${ }^{3}$ The GPx activity was measured with a kit of GPx detection according to the manufacturer's instructions. The GPx was evaluated spectro photometrically at $340 \mathrm{~nm}$, which was expressed in U/mg protein. ${ }^{4}$

\section{Histopathological Examination}

The tissue of heart was fixed in a $10 \%$ solution of neutral buffered formalin, embedded in paraffin and stained with used hematoxylin and eosin for histopathological examination. ${ }^{2,3}$

\section{Statistical Analysis}

Data were shown as mean \pm standard deviation (mean \pm SD) and analyzed with one-way ANOVA. The statistical comparisons among the groups were carried out with a least significant difference (LSD) test (SPSS V. 17.0). 


\begin{abstract}
RESULTS AND DISCUSSION
Characterization of Nanoparticles by Scanning Electron Microscopy and by Dynamic Light Scattering

Nanotechnology is the term given to those areas of science and engineering in which materials are designed at nanometer range. The nanotechnology was new advances in technology which now can be used to produce natural product nanoparticles. Nanoparticle-based natural product may enhance drug bioavailability, solubility, stability and efficacy compared to a pure natural product. ${ }^{22}$

The variously of polymers can be utilized for herbal extract-loaded nanoparticles, however, chitosan has a role important in both the pharmaceutical and medical field. ${ }^{21}$ We made Pinus merkusii extract was encapsulated into chitosan nanoparticle with use sodium tripolyphosphate on ionotropic gelation method, which has more advantages over Pinus merkusii extract.

Scanning Electron Microscopy(SEM) images of the nanoparticles prepared using ionic gelation revealed that the nanoparticle surface showed the rough surface morphology and irregular shape (Fig.-1). Recent nanoparticle technology has enabled for the production of nanoparticle with unique size, shape, and materials, which in turn has facilitated major advancements in the research of nanomedicine.
\end{abstract}

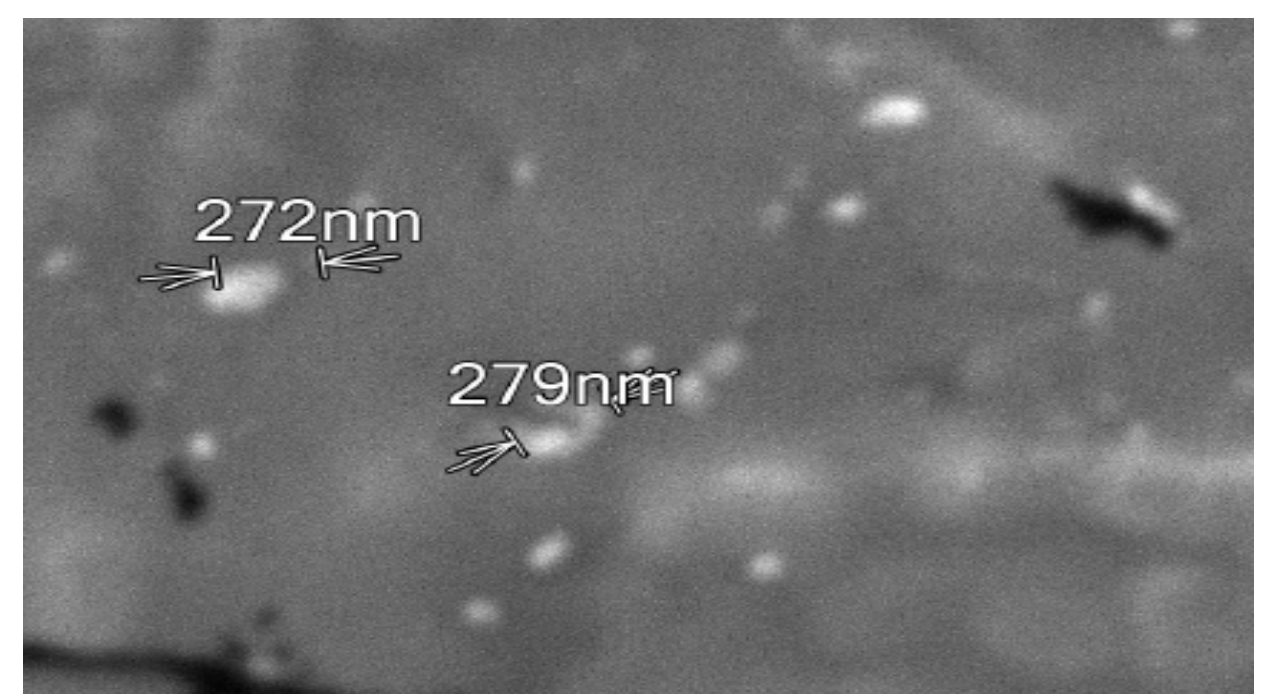

Fig.-1: Scanning Electron Microscope Image of Chitosan-Pinus Merkusii Extract nanoparticles

Nanoparticles have been widely used in the field of medical, pharmaceutical as well as for therapeutic purposes because nanoparticles have very small sized particles. The size of nanoparticles is $<1000 \mathrm{~nm}$ that have specific physicochemical properties different to pure materials of the same composition and such properties make them very attractive for pharmaceutical and medical development.

The Chitosan-Pinus merkusii extract nanoparticles have average particle size $201.8 \pm 14.6 \mathrm{~nm}$ on Dynamic Light Scattering as shown in Fig.-2.

Due to this modification can improve bio distribution and increase specificity and sensitivity, and reduced pharmacological toxicity. ${ }^{15,26,30}$

\title{
Effects of Chitosan-Pinus Merkusii Extract Nanoparticle on Lead Acetate-induced Changes in CK- MB and LDH
}

Table-1 showed the results of CK-MB and LDH level in all groups. In the lead acetate group, increased of CK-MB and LDH significantly $(\mathrm{P}<0.05)$ when compared with the control group. However, in the treatment with Chitosan-Pinus merkusii extract nanoparticle at dose $400 \mathrm{mg} / \mathrm{kg} \mathrm{BW}$ but not at dose 100 $\mathrm{mg} / \mathrm{Kg}$ and $200 \mathrm{mg} / \mathrm{kg} \mathrm{BW}$ showed a significant decrease $(\mathrm{P}<0.05)$ in CK-MB and LDH level when compared to the lead acetate group.

The results suggest that the lead acetate administration can increase CK-MB and LDH level in serum, which indicated that lead acetate-caused oxidative stress leading to lipid peroxidation increasing that can 
damage cardiac cells and releases CK-MB and LDH. Whereas the treatment with Chitosan-Pinus merkusii extract nanoparticle can inhibit the formation of ROS and oxidative damage in the cardiac cell, so CK-MB and LDH level in serum decreasing.

Size Distribution by Intensity

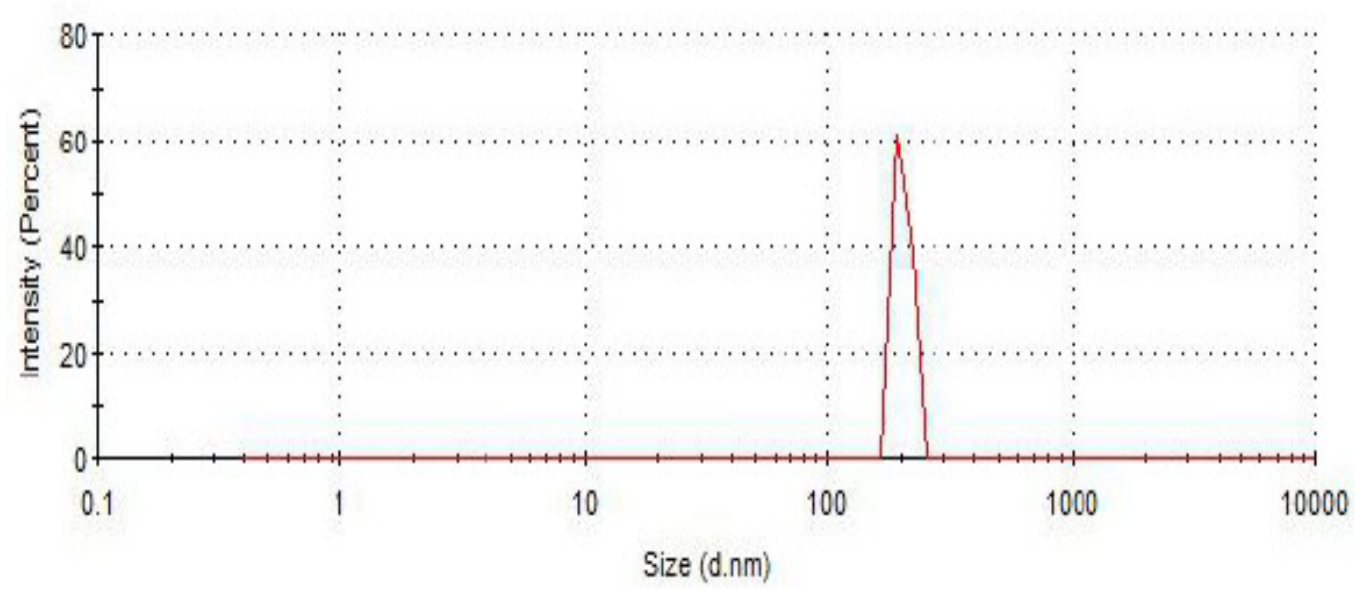

Fig.-2: Size Distribution of Chitosan-Pinus Merkusii Extract Nanoparticles by Dynamic Light Scattering.

Table-1: Cardioprotective Effect of Chitosan-Pinus merkusii Extract Nanoparticle on CK-MB and LDH

\begin{tabular}{ccc}
\hline Group & CK-MB (IU/L) & LDH (IU/L) \\
\hline Negative Control & $61.7^{\mathrm{a}} \pm 5.34$ & $96.7^{\mathrm{a}} \pm 7.34$ \\
Positive Control & $99.6^{\mathrm{b}} \pm 7.52$ & $149.6^{\mathrm{b}} \pm 12.52$ \\
Chit- $P$. merkusii Nano 100 mg/kg BW & $93.3^{\mathrm{b}} \pm 6.71$ & $143.3^{\mathrm{b}} \pm 9.71$ \\
Chit- $P$. merkusii Nano 200 mg/kg BW & $86.8^{\mathrm{b}} \pm 5.26$ & $136.8^{\mathrm{b}} \pm 8.26$ \\
Chit- $P$. merkusii Nano 400 $\mathrm{mg} / \mathrm{kg} \mathrm{BW}$ & $73.2^{\mathrm{c}} \pm 4.69$ & $121.2^{\mathrm{c}} \pm 8.69$ \\
\hline men
\end{tabular}

a,b,c Different superscript within each column indicate a significant difference between the means $(P<0.05)$

\section{Effects of Chitosan-Pinus merkusii Extract Nanoparticle on Lead Acetate-induced Changes in} MDA, SOD, and GPx of Heart Tissue

In this study, we investigated the protective effect of Chitosan-Pinus merkusii extract nanoparticle on the administration of lead acetate-induced the oxidative stress changes in the heart tissue in rats. Table 2 showed the results of the MDA level of heart tissue in all groups. In the lead acetate group, the MDA level of heart tissue significantly increasing were compared with the control group $(\mathrm{P}<0.05)$. The lead acetate-induced toxic effect in biological systems have been related to increased MDA level as the final products of lipid peroxidation through the generation of free radical, including hydro peroxides, singlet oxygen, and hydrogen peroxide, and the direct depletion of antioxidant reserves. ${ }^{2,3,6,8}$ This means that it occurs increased the oxidative stress in the lead acetate group rats. The treatment of Chitosan-Pinus merkusii extract nanoparticle significantly lowered MDA level in the heart tissues were compared with the lead acetate group, it indicated attenuation of lipid peroxidation (Table 2). Treatment with ChitosanPinus merkusii extract nanoparticle at dose $400 \mathrm{mg} / \mathrm{Kg} \mathrm{BW}$ but not at dose $100 \mathrm{mg} / \mathrm{Kg}$ and $200 \mathrm{mg} / \mathrm{kg}$ BW markedly reduced heart tissue MDA in lead acetate treatment which was significantly different from the control group $(\mathrm{P}<0.05)$.

It has been reported that lead acetate caused oxidative stress and tissue damage could be related with two mechanisms including increased generation of Reactive Oxygen Species (ROS) and direct depletion of antioxidant reserves. ${ }^{4}$ The lipid peroxidation can be increased by lead acetate administration, which may affect the cytoplasmic membranes and mitochondrial, causing more severe oxidative damage in the tissues ${ }^{5,8}$ In this study, Chitosan-Pinus merkusii extract nanoparticle have powerful antioxidant and free radical scavenger can decrease the MDA level induced by lead acetate in rats heart. Treatment of rats 
with Chitosan-Pinus merkusii extract nanoparticle prevented the MDA level to rise when the rats were challenged with lead acetate. This means that Chitosan-Pinus merkusii extract nanoparticle inhibited the toxic effect of lead acetate through its antioxidant activity. The mechanism of antioxidant protective decreases the oxidative stress and scavenges the free radical responsible for the hearts damage and thus inhibit the lipid peroxidation as measured by MDA levels. The findings of this study suggest that Chitosan-Pinus merkusii extract nanoparticle could inhibit oxidative stress by decreasing the MDA level (lipid peroxidation) in the lead acetate treated heart.

Table-2: Effects of Chitosan-Pinus merkusii Extract Nanoparticle on Lead Acetate induced Changes in the Malondialdehyde, Superoxide Dismutase and Glutathione Peroxidase

\begin{tabular}{l|c|c|c}
\hline \multirow{2}{*}{ Groups } & \multicolumn{3}{c}{ Means \pm Standard Deviation } \\
\cline { 2 - 4 } & $\begin{array}{c}\text { SOD } \\
\text { (U/mg tissue) }\end{array}$ & $\begin{array}{c}\text { GPx } \\
\text { (U/mgtissue) }\end{array}$ & $\begin{array}{c}\text { MDA } \\
\text { (nmol/mg tissue) }\end{array}$ \\
\hline Negative Control & $9.21^{\mathrm{a}} \pm 1.03$ & $0.96^{\mathrm{a}} \pm 0.10$ & $47.83^{\mathrm{a}} \pm 3.15$ \\
Positive Control & $5.17^{\mathrm{b}} \pm 0.92$ & $0.54^{\mathrm{b}} \pm 0.12$ & $71.14^{\mathrm{b}} \pm 6.13$ \\
Chit-P. merkusii Nano 100 mg/kg BW & $4.42^{\mathrm{b}} \pm 1.13$ & $0.48^{\mathrm{b}} \pm 0.11$ & $68.23^{\mathrm{b}} \pm 4.12$ \\
Chit-P. merkusii Nano 200 mg/kg BW & $5.12^{\mathrm{b}} \pm 0.81$ & $0.59^{\mathrm{b}} \pm 0.18$ & $62.82^{\mathrm{b}} \pm 4.39$ \\
Chit-P. merkusii Nano 400 mg/kg BW & $7.17^{\mathrm{c}} \pm 1.07$ & $0.79^{\mathrm{c}} \pm 0.11$ & $54.12^{\mathrm{c}} \pm 3.42$ \\
\hline
\end{tabular}

a,b,c, $\overline{\text { Different superscript within each column indicate a significant difference between the means }(P<0.05)}$

The activities of SOD, and GPx have been associated to occur oxidative stress in cells. Many studies have reported that lead acetate inhibiting functional SH groups in several enzymes such as SOD, and GPx, thus it can decrease antioxidant activities. ${ }^{1}$ In the present study, Table-2 also showed the results of the lead acetate group, the SOD, and GPx level of heart tissue significantly decreased were compared with the control group $(\mathrm{P}<0.05)$. The treatment with Chitosan-Pinus merkusii extract nanoparticle at dose $400 \mathrm{mg} / \mathrm{Kg} \mathrm{BW}$ but not at dose $100 \mathrm{mg} / \mathrm{Kg}$ and $200 \mathrm{mg} / \mathrm{kg} \mathrm{BW}$ markedly increased SOD, and GPx level of heart tissue in lead acetate treatment which was significantly different from the lead acetate group $(\mathrm{P}<0.05)$. This decreased SOD, and GPx activities with lead acetate treatment is in agreement with previous research. This suggested that lead acetate exposure can inhibit the activity of antioxidant enzyme so induced oxidative stress. ${ }^{9}{ }^{10}$ However, the Chitosan-Pinus merkusii extract nanoparticle administration increased the SOD, and GPx level in the heart tissue of lead acetate-treated rats, which might be due to the ability of Chitosan-Pinus merkusii extract nanoparticle to decrease the free radicals. Chitosan-Pinus merkusii extract nanoparticle acts as a scavenger for the free radicals, thus inhibiting heart tissue damage. The decrease in lipid peroxidation due to Chitosan-Pinus merkusii extract nanoparticle administration has been related with the antioxidant defense system such as SOD, and GPx, which normally protect toxicity of free radical.

The administration of Chitosan-Pinus merkusii protected cardiac damage through SOD and GPx which can a membrane stabilizing effect and this supported by decreasing CK-MB and LDH activities. Thus membrane stabilization would inhibit the mobility of lipid peroxyl radicals and would restrict to interact with adjacent membrane polyunsaturated fatty acids.

\section{Effects of Chitosan-Pinus merkusii Extract Nanoparticle on Lead Acetate induce Cardiac Cell Damage}

It has been reported by some researchers that heavy metal toxicity such as lead acetate on structural changes in heart tissue in histopathological. In the present study, histological observations on the negative control showed that cardiac cell is observable and they appear normal architecture of the muscle fibers. In the positive control, rats were administered only with lead acetate showed cardiac cell damage (necrosis). In the rats, treated with Chitosan-Pinus merkusii extract nanoparticle, the number and morphological integrity of cardiac cells are being preserved. The heart damage (necrosis) was considered mild in the groups treated with Chitosan-Pinus merkusii extract nanoparticle $400 \mathrm{mg} / \mathrm{kg}$. Observations indicate that the cardio toxic effects lead acetate was reduced by Chitosan-Pinus merkusii extract nanoparticle (Fig.-3). 


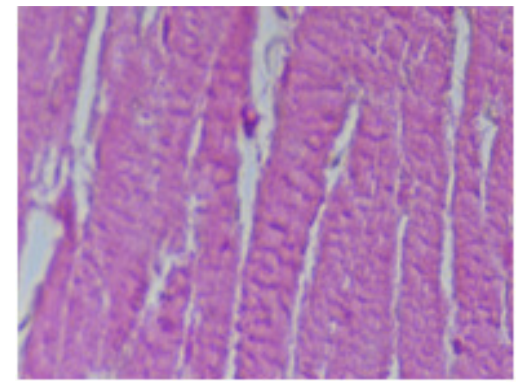

A

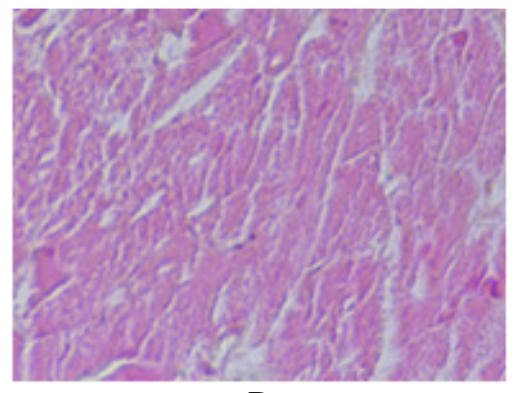

$\mathrm{D}$

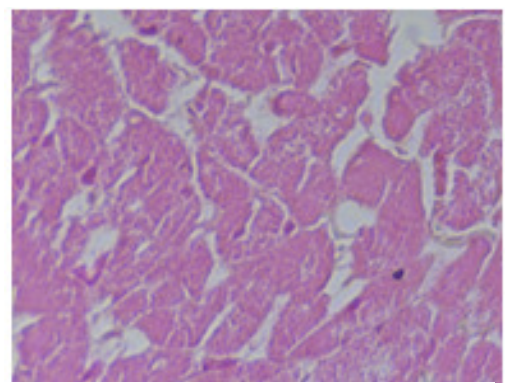

$\mathrm{B}$

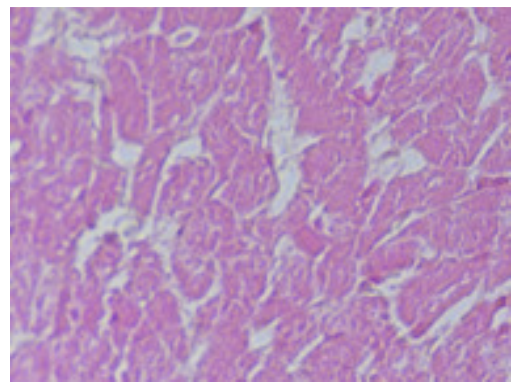

$\mathrm{C}$

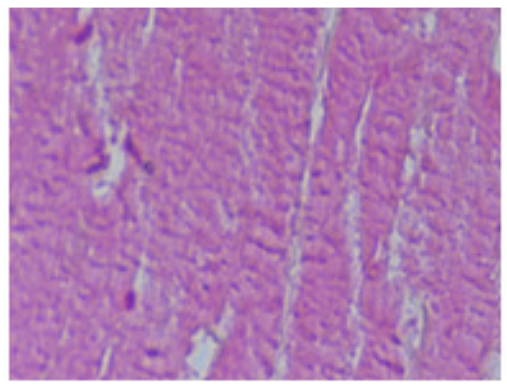

$\mathrm{E}$

Fig.-3: Histological Study of Pretreatment with Chitosan-Pinus merkusii Extract Nanoparticle on Lead Acetate caused Cardiotoxicity. (A) Normal Morphology of Heart Sections in the Control Group, (B) The Lead Acetate Group showed Necrosis (indicated by arrows), (C) and (D) The Treatment with Chitosan-Pinus merkusii Extract Nanoparticle $100 \mathrm{mg} / \mathrm{kg} \mathrm{BW}$ and $200 \mathrm{mg} / \mathrm{kg} \mathrm{BW}$ respectively showed necrotic changes, (E) The Treatment with Chitosan-Pinus merkusii Extract Nanoparticle $400 \mathrm{mg} / \mathrm{kg}$ showed Inhibition in Cardiac Cells Damage. H\&E $\times 400$

\section{CONCLUSION}

The results of the present study indicate that lead acetate-induced heart toxicity can be associated with oxidative stress. The treatment with Chitosan-Pinus merkusii extracts nanoparticle can protect on lead acetate-induced cardiac cell damage through inhibiting the free radical and increasing antioxidant enzyme. Further protective effects of Chitosan-Pinus merkusii extract nanoparticle may be developed clinically to treat patients with lead acetate-induced heart failure.

\section{ACKNOWLEDGMENT}

We are gratefully thankful to Airlangga University, Indonesia for supporting this study.

\section{REFERENCES}

1. F. Gagan, G. Deepesh and T. Archana, Interdiscip. Toxicol.,5, 47(2012), DOI:10.2478/v10102-0120009-2

2. S. A. Sudjarwo, K. Eraiko, G. Wardani and Koerniasari, Iran J. Basic Med. Sci., 20,1227(2017), DOI: $10.22038 / \mathrm{IJBMS} .2017 .9487$

3. G. Wardani, N. Farida, R. Andayani, M. Kuntoro and S.A. Sudjarwo, Pharmacogn. Res., 9, 282(2017), DOI: 10.4103/pr.pr_69_16

4. S. A. Sudjarwo, G. Wardani and Koerniasari, Res. Pharm. Sci., 12(5), 381(2017), DOI: $10.4103 / 1735-5362.213983$

5. N. D. Vaziri, Am. J. Physiol: Heart and Circulatory Physiology., 295, H454(2014), DOI: 10.1152/ ajpheart.00158.2008

6. D. Ghosh, S. B. Firdaus, E. Mitra, M. Dey, A. Chattopadhyay and S.K. Pattari, Int. J. Phytopharmacol., 4(2),119(2013) 
7. A. Marwa, Ahmed, M. Khaled and A. Hassanein, J. Physiol. Pathophysiol., 4(5), 72(2013), DOI: 10.5897/JPAP2013.0083

8. D. Ghosh, E. Mitra, S.B. Firdaus, A.K. Ghosh, A. Chattopadhyay and S.K. Pattari, Int. J. Pharm. Pharm. Sci., 5(3), 806(2013)

9. P. Sugita, S. Arya, A. Ilmiawati and B. Arifin, Rasayan J. Chem., 10(3), 707(2017), DOI: $10.7324 /$ RJC.2017.1031766

10.Z. H. Geng, L. Huang, M. B. Song and Y. M. Song, Carbohydr. Polym., 132, 638(2015), DOI:10.1016/j.carbpol.2015.06.086

11.G. M. Cragg and D.J Newman, Biochim. Biophys. Acta., 1830, 3670(2013), DOI: 10.1016/ j.bbagen.2013.02.008

12.S. P. Saberi, P.P. Farzanegi, P.S. Ranjbar, P.A. Gholizade and P.A. Talebolhagh-Kakh, Zahedan J. Res. Med. Sci., 15(11), 45(2013)

13.M. Qadir and W.A. Shah, Int. J. Res. Pharm. Chem., 4(1), 228(2014), DOI: 10.7439/ijpr.v4i2.87

14.Y.Y. Li, J. Feng, X.L. Zhang and Y.Y. Cui, J. Pharmacol. Exp. Ther., 353, 9(2015), DOI: 10.1124/jpet.114.220277

15.S.A. Sudjarwo, G. Wardani, K. Eraiko and Koerniasari, Int. J. Nutr. Pharmacol. Neurol. Dis., 8,10(2018), DOI: 10.4103/ijnpnd.ijnpnd_72_17

16.C.S. Ku and S.P. Mun, Wood Sci. Technol., 41,235(2007), DOI:10.1007/s00226-006-0103-8

17.N.Y. Kim, M.K. Jang, D.G. Lee, K.H. Yu, H.J. Jang and S.H. Lee, Nutr. Res. Pract., 4(1), 16(2014), DOI: $10.4162 / \mathrm{nrp} .2010 .4 .1 .16$

18.I. Ince, O. Yesil-Celiktas, N.U. Karabay-Yavasoglu and G. Elgin, Phytomed.,16,1101(2009), DOI: 10.1016/j.phymed.2009.05.004

19.I.J. Park, S.Y. Cha, M. Kang, Y.S. So, S.P. Mun, K.S. Ryu and H.K. Jang, Poult. Sci., 90,977(2011), DOI: $10.3382 /$ ps.2010-01160.

20.T.U. Rahman, G. Uddin, K.F. Khattak, W. Liaqat and M.I. Choudhary, J. Chem. Pharm. Res., 8(1), 420(2016)

21.N. Karikalan, Rasayan J. Chem., 11(4), 1451(2018), DOI:10.31788/ RJC.2018.1143068

22.A. Kumari and V. Kumar, Trends. Med. Res., 7(2), 34(2012), DOI:10.3923/tmr.2012.34.42

23.M. Friedman and V.K. Juneja, J. Food Prot., 73(9),1737(2010), DOI: 10.4315/0362-028X-73.9.1737

24.T.A. Ahmed and B.M. Aljaeid, Drug Des. Devel. Ther., 10,483(2016), DOI: 10.2147/DDDT.S99651

25.A. Ghadi, S. Mahjoub, F. Tabandeh and F. Falebnia F. Caspian, J. Intern. Med., 5(3), 156 (2014).

26.M. Khan mohammadi, H. Elmizadeh and K. Ghasemi, Iran. J. Pharm. Res., 14(3), 665(2015).

27.G. Wardani, Mahmiah and S.A. Sudjarwo, Pharmacogn J., 10(1), 162(2018), DOI:10.5530/ pj.2018.1.27

28.I. Younes and M. Rinaudo, Mar. Drugs., 13(3),1133(2015), DOI: 10.3390/md13031133

29.K. Sudheesh, A.K. Mishra, O.A. Arotiba and B.B. Mamba, Int. J. Biol. Macromol., 59,46(2013), DOI:10.1016/j.ijbiomac.2013.04.043

30.S. Vimal, S.A. Majeed, G. Taju, M.A. Farook, T. Rajkumar and D. Gopinath, Acta Trop., 128(3),486(2013), DOI:10.1016/j.actatropica.2013.07.013

[RJC-5049/2018] 